\section{SAT0190 HFE GENOTYPE IN PATIENTS WITH RHEUMATIC DISEASES}

MM Etemad, UH Hanusch-Enserer, KC Cauza, AD Dunky, EC Cauza. Department of Rheumatology/Medicine 5, Wilhelminenspital, Vienna, Austria

\subsection{6/annrheumdis-2001.688}

Background Hereditary haemochromatosis is a very common autosomal recessive disorder of iron metabolism. Among Northern Europeans the carrier frequency is estimated 1 in 10 , while up to 1 in 200 are affected by the disease. Arthropathy is one early clinical manifestation of this disease (the spectrum ranged from arthralgia to classic polyarthrits), but the articular features are often misdiagnosed. We tested the usefulness of measuring the HLA-linked haemochromatosis gene (HFE) in rheumatology clinic population.

Objectives

Methods Over a period of 12 month 203 consecutive patients, mean age 62.0 years (33 male/170 female) attending our rheumatologic clinic were screened for HFE mutations (C282Y and H63D). Mutations were evaluated by separation on PAGE of digest (by SnapI and Bcl-I, for C282Y and H63D, respectively) of PCR-amplificates of DNA obtained from PBMC's.

Results The C282Y and H63D allele frequencies were 6.9 and 18.2 in patients with rheumatic diseases. Five patients were homozygote for $\operatorname{H63D}(2.5 \%), 1$ for $\mathrm{C} 282 \mathrm{Y}(0.5 \%)$. Three patients were compound heterozygotes (1.4\%). Diagnosis of patients are summarised in Table 1. The observed C282Y allele frequency in rheumatic patients with undifferentiated arthritis exceeded that of healthy subjects or patients with chronic hepatitis $\mathrm{C}$ in Austria. ${ }^{1}$

\begin{tabular}{llllll}
\multicolumn{6}{l}{ Abstract SAT0190 Table 1} \\
\hline & C282Y/WT & H63D/WT & H63D/H63D & C282Y/C282Y & WT/WT \\
\hline Osteoarthritis & 14 & 21 & 4 & 0 & 82 \\
Undifferentiated & 0 & 0 & 0 & 1 & 5 \\
Rheumatoid & 1 & 12 & 1 & 0 & 47 \\
Psoriatic & 1 & 4 & 0 & 0 & 6 \\
Collagenosis & 0 & 0 & 0 & 0 & 3 \\
Temporal & 0 & 0 & 0 & 0 & 1 \\
Total & 16 & 37 & 5 & 1 & 144 \\
\hline Distribution of HFE Gene Mutation in 203 rheumatologic patients.
\end{tabular}

Conclusion Determination of HFE genotype is clinically useful in the group of patients with undifferentiated peripheral arthropathy and may lead to identification of otherwise unsuspected C282Y homozygotes.

\section{REFERENCE}

1 Kazemi, et al. Gastroenterology 1999;116(1):12-34

\section{SAT0191 QUANTITATIVE ULTRASOUND OF THE CALCANEUS IN PORTUGUESE CHILDREN AND ADOLESCENTS}

MM Costa, P Nero, E Branco, J Branco. Rheumatology, Hospital Egas Moniz, Lisbon, Portugal

10.1136/annrheumdis-2001.689

Background
Objectives The aim of this study was to determine value range of the parameters SOS, BUA and stiffness for Portuguese children and adolescents in age, sex and race groups.

Methods The study included 473 healthy children coming from two Lisbon schools. The population was $92,2 \%$ caucasian. There were $261(55,2 \%)$ girls and $212(44,8 \%)$ boys. Mean age was $10,7+2,4$ year, range 6-17 yr. The Sahara Clinical Sonometer of Hologic was used to performed a quantitative ultrasound (QUS) measurement of the non-dominant calcaneus. Patient examination was performed by two rheumatologists.

Results The mean of BUA, SOS and stiffness were: $70.07+19.82$ $\mathrm{db} / \mathrm{MHz}, 1563.64+26.65 \mathrm{~m} / \mathrm{s}$ and $98.96+17.7$.

There were no statistical differences between sex or race in each groups.

We observed an increased BUA, SOS and stiffness from 6 to 9 $\mathrm{yr}$ in caucasian boys and then stabilised. At this time the means were respectively $81.06 \mathrm{db} / \mathrm{MHz}, 1582 \mathrm{~m} / \mathrm{s}$ and 110.86 . In caucasian girls the increase of values occurred two years later and until 14 yr. The Spearman's rho correlation coefficient shown, in caucasian girls, a influence of age, height and weight on QUS parameters. In boys, this factors affect only SOS and stiffness. There were no correlation with this factors in black.

\begin{tabular}{llllll}
\multicolumn{6}{l}{ Abstract SAT0191 Table 1} \\
\hline & $\begin{array}{l}\text { Caucasian Girls } \\
(\mathbf{n}=240)\end{array}$ & $\begin{array}{l}\text { Caucasian Boys } \\
(\mathbf{n}=196)\end{array}$ & $\begin{array}{l}\text { Black Girls } \\
(\mathbf{n}=21)\end{array}$ & $\begin{array}{l}\text { Black Boys } \\
(\mathbf{n}=16)\end{array}$ & $\begin{array}{l}\text { Total } \mathbf{n}= \\
473\end{array}$ \\
\hline BUA & $69.14 \pm 18.49$ & $70.12 \pm 20.44$ & $76.99 \pm$ & $74.21 \pm$ & $70.07 \pm$ \\
& & & 26.07 & 21.85 & 19.82 \\
SOS & $1561.71 \pm 24.16$ & $1563.65 \pm 27.83$ & $1569.23 \pm$ & $1584.93 \pm$ & $1563.64 \pm$ \\
& & & 39.42 & 17.77 & 26.65 \\
Stiffness & $97.65 \pm 15.55$ & $99.20 \pm 19.26$ & $103.95 \pm$ & $109.25 \pm$ & $98.97 \pm$ \\
& & & 25.23 & 14.99 & 17.77 \\
BMD & 0.541 & $0.551 \pm 0.122$ & $0.581 \pm$ & 0.614 & $0.549 \pm$ \\
& & & 0.159 & & 0.112 \\
\hline
\end{tabular}

Conclusion Measuring bone mass of children by QUS is good technique. However reference data ranges must be developed for each population.

\section{SAT0192 RELATIONSHIP BETWEEN CLINICALLY DETECTED JOINT SWELLING AND EFFUSION DIAGNOSED BY ULTRASONOGRPAHY IN TALOCRURAL JOINTS IN PATIENTS WITH RHEUMATOID ARTHRITIS}

${ }^{1}$ RK Luukkainen, ${ }^{2} \mathrm{H}$ Huhtala, ${ }^{3} \mathrm{JM}$ KoskiHuhtala. 'Department of Rheumatology, Satalinna Hospital, Harjavalta; ${ }^{2}$ School of Public Health, University of Tampere, Tampere; ${ }^{3}$ Depatment of Medicine, Central Hospital of Mikkeli, Mikkeli, Finland

10.1136/annrheumdis-2001.690

Background In clinical investigation it is often difficult to know if there is effusion in talocrural (TC) joint or not.

Objectives To compare the relationship between clinically detected swelling and effusion diagnosed by ultrasonography (US) in TC joints in patients with rheumatoid arthritis (RA).

Methods Thirty-one consecutive patients with RA entered the study. Twenty healthy persons formed a control group. In clinical assessment the TC joint was evaluated on the scale: normal or swelling. The US of the same joints was carried out. Altogether 62 TC joints of the RA patients and 40 of those of the controls were studied. All the clinical assessments were performed by one 
doctor and the US investigations by another and they were blinded of one others results.

Results Normal upper limit of the measurement between the talus and the joint capsule was evaluated from the control group. It was $3.1 \mathrm{~mm}$ (mean $+2 \mathrm{SD}$ ) and only two TC joints of the normal persons had a value above it $(4.1$ and $5.4 \mathrm{~mm})$. So, if the noechogenic space between the talus and the joint capsule was $3.1 \mathrm{~mm}$ or less, it was regarded as normal and if it was 3.2 $\mathrm{mm}$ or more, it was regarded as effusion. The clinical assessment and the US gave similar results in 35 TC joints, whereas they differed in the remaining 27 joints. The kappa coefficient between these investigations was 0.039 showing extremely poor agreement.

Conclusion These preliminary results indicate that clinical evaluation is not adequate in diagnosis of effusion and synovitis of TC joints in patients with RA. It is probable that the main source of error in this respect is tenosynovitis in the region of ankle. So, US may significantly mprove the accuracy of diagnosis of effusion and synovitis in these patients.

\section{SAT0193 PULMONARY FUNCTION TESTS IN PATIENTS WITH CONNECTIVE TISSUE DISEASES}

K Borysewicz. Department of Rheumatology, Medical Academy of Wrockaw, Wrockaw, Poland

\subsection{6/annrheumdis-2001.691}

Background In connective tissue diseases many systems and organs are involved. Pleural effusion, interstitial pneumonia, pulmonary vasculitis, rheumatoid nodules, obliterative bronchiolitis, pulmonary hypertension and pulmonary fibrosis may be found in patients with connective tissue diseases. Quality of life, effort tolerance and frequency of bronchial or lung infection depends on good pulmonary function.

Objectives The aim of this study was to examinate the spirometry indices in patients with connective tissue diseases.

Methods 80 persons: 40 with rheumatoid arthritis (RA), 11 with systemic lupus erythematosus (SLE), 8 with diffuse scleroderma, 3 with scleromyositis, 10 with ankylosing spondylitis (AS) and 8 with polymyositis were examined. The following parameters were measured: VC, ERV, FEV1, FVC, FEV1\%VC, MEF 25, 50 and 75, MEF 25/75, MVV, MEF 50\%FVC. Pulmonary function tests were done on spirometer abcPNEUMO PC in accordance with European Respiratory Society. All patients have normal blood gases values and chest X-ray.

Results In RA patients spirometric indices were in normal ranges, although the lowest values were in FEV1 and FVC. In active RA (elevated ESR and CRP) and long-term diseases maximum voluntary ventilation (MVV) was below the normal ranges. There was no ventilation disturbances in patients long-term treated with methotrexate who are in remission.

In SLE patients, all were in remission, there was no ventilation abnormalities.

AS, diffuse scleroderma and scleromyositis patients produce a restrictive spirometric defect.

The most restrictive disturbances were found in patients with active polymyositis.

MVV was the lowest values in patients with III or IV musculosceletal functional class.

There were more frequency of bronchial or pulmonary infections in patients with long-term diseases. This was not connected with immunosupressive therapy.

\section{Conclusion}

- Pulmonary function tests allow to early identification of ventilation disturbances in patients with connective tissue diseases.

- The long-term diseases have an influence on ventilation disturbances.

- Restrictive defect is the main ventilation abnormalities in connective tissue diseases.

- The most spirometric indices changes are found in active polymyositis.

- Musculosceletal functional status is important in lowering the MVV.

- Patients with connective tissue diseases have more frequent respiratory infections.

\section{SAT0194 HPLC METHOD FOR PENTOSIDINE DETERMINATION IN URINE AND SERUM}

P Spacek, M Adam. Connective Tissue Research, Institute of Rheumatology, Prague 2, Czech Republic

10.1136/annrheumdis-2001.692

Background Pentosidine (PEN) is the most known representative from the so-called AGE derivatives, whose concentration is elevated in some pathological conditions, ${ }^{1}$ (e.g. in diabetes, renal failure, osteoarthritis (OA), inflammatory diseases, etc.). PEN determination is therefore often used for characterisation of the disease activity.

Objectives The aim of this study is to elaborate precise and sensitive HPLC method for PEN determination, apply it the for evaluation in urine samples in the OA patients and in healthy controls, and to test possible correlation between urine pyridinoline ${ }^{2}$ and pentosidine.

Methods Liquid chromatograph of the firm SHIMADZU type CLASS VP version 5.0 was on line controlled by means of special software in Windows 98 milieu. Glass column Separon SGX C18, $150 \times 3 \mathrm{~mm}$ (Tessek, Prague, Czech Republic) as the stationary phase and mobile phase $0.02 \mathrm{M}$ heptafluorobutyric acid (HFBA), $0.01 \mathrm{M}$ (NH4)2SO4 with variable acetonitrile (ACN) concentration was used.

Results Pentosidine standard was synthesised utilising simple polymer analogical reaction and kindly quantified by HPLC in foreign lab. ${ }^{3}$ Variation in the reproducibility (RSD) of the HPLC alone was slightly above $1 \%$, RSD of the whole method (i.e. including sample hydrolysis and purification) was $4.44 \%$, recovery was $77 \pm 3.5 \%$, HPLC sensitivity limit was 17.6 femtomoles.

Urine PEN concentrations were determined in the OA patients $(\mathrm{N}=37$, age $66.97 \pm 9.89$ years $)$ and in control individuals $(\mathrm{N}=15$, age $30.01 \pm 8.67$ years $)$. $\mathrm{PEN}$-age dependence was eliminated by extrapolation in the sense of known measured PEN-age dependence. ${ }^{4}$ In OA PEN urine concentrations were significantly higher (almost four times) compared with healthy controls $(8.0 \pm 7.2$ vs. $2.1 \pm 0.5 \mathrm{nmol} / \mathrm{mmol}$ creat., $\mathrm{P}=$ 0.00002). Slight correlation exists between urinary pentosidine and urinary pyridinoline in OA (U-PEN $=0.0773 \% \mathrm{U}-\mathrm{PD}$ $+2.2595, \mathrm{r}=0.4$ ), probably partially evoked by immunity response of the organism due to the toxic action of PEN-containing molecular domains, ${ }^{5,6}$ sary leading to accelerated resorption kinetics and thus to the additional increasing pyridinoline level.

Conclusion Sensitive and accurate HPLC method for pentosidine determination was elaborated, optimised and quantified with 